\title{
ANALISA SWOT DAN STRATEGI PEMASARAN YANG DI TERAPKAN PT PANEN MAS INDONESIA DAN DAMPAKNYA TERHADAP KEPUASAN DAN KESETIAAN PELANGGAN
}

\author{
Reyner Perdana \\ Program Studi Magister Manajemen Universitas Tarumanagara \\ reyner.perdana704@gmail.com
}

Masuk : 07-06-2020, revisi : 26-06-2020 diterima untuk diterbitkan : 29-06-2020

\begin{abstract}
Business activity is an activity carried out with the aim of getting profit. Types of business activities are divided into two, seen from the products produced by these business activities, namely goods and services. One of the businesses in the service sector is the business carried out by PT Panen Mas Indonesia, a company engaged in the rental of event contracting equipment. The contracting equipment leased by PT Panen Mas Indonesia includes 3 types of equipment, namely: generator set, air conditioner, tent. Applying the right marketing strategy becomes important in an effort to achieve maximum customer satisfaction and loyalty, and can increase the number of company customers, the purpose of this study is to find out whether the SWOT factor, and the marketing strategies applied by the company have an impact on customer loyalty and satisfaction. This research is a qualitative study, by conducting in-depth interviews with company owners, and the company's administration and Focus Group Discussion (FGD) with a total of 10 customers of PT Panen Mas Indonesia customer in the Greater Jakarta area which are divided into two groups. Where the first group is customers who use the company's services above three times, and the second group of customers who use the company's services below or equal to three times. The research data was validated by the triangulation method. From the research results it is known that SWOT and marketing strategies applied are Word of Mouth, and promotion. The company also participates in business fairs, but it has not been done routinely so that it has not gotten maximum results, from the research results it is known that the company does not have an official office, and does not yet have a marketing division.
\end{abstract} Keywords: SWOT, Sales Marketing, In-depth interview, Focus Group Discussion, Triangulation

\begin{abstract}
Abstrak: Kegiatan usaha merupakan suatu kegiatan yang dilakukan dengan tujuan mendapatkan keuntungan. Jenis kegiatan usaha dibagi menjadi dua dilihat dari produk yang dihasilkan oleh kegiatan usaha tersebut, yaitu barang dan jasa. Salah satu usaha di bidang jasa adalah usaha yang di lakukan PT Panen Mas Indonesia (exhibition contractor), merupakan perusahaan yang bergerak di bidang jasa penyewaan alat kontraktor acara. Alat kontraktor yang di sewakan oleh PT Panen Mas Indonesia meliputi 3 jenis alat, yaitu: genset, air conditioner, tenda. Penerapan strategi pemasaran yang tepat menjadi penting dalam upaya untuk mencapai kepuasan dan kesetiaan pelanggan yang maksimal, serta dapat meningkatkan jumlah pelanggan perusahaan maka tujuan penelitian ini adalah untuk mengetahui apakah faktor SWOT, dan strategi pemasaran yang di terapkan perusahaan berdampak kepada kesetiaan dan kepuasan pelanggan. Penelitian ini merupakan penelitian kualitatif, dengan melakukan in-depth interview kepada pemilik perusahaan, dan bagian administrasi perusahaan dan Focus Group Discussion $(F G D)$ dengan total 10 pelanggan pengguna jasa PT Panen Mas Indonesia di wilayah JABODETABEK yang di bagi menjadi dua kelompok. Dimana kelompok pertama merupakan pelanggan yang menggunakan jasa perusahaan diatas tiga kali, dan kelompok kedua pelanggan yang menggunakan jasa perusahaan di bawah atau sama dengan tiga kali. Adapun data penelitian ini divalidasi dengan metode triangulasi. Dari hasil penelitian diketahui SWOT dan strategi pemasaran yang diterapkan adalah Word of Mouth, dan promosi.
\end{abstract}


Perusahaan juga mengikuti pameran usaha namun masih belum di lakukan secara rutin sehingga belum mendapatkan hasil yang maksimal, dari hasil penelitian diketahui bahwa perusahaan belum memiliki kantor yang resmi, dan belum memiliki divisi pemasaran.

Kata kunci: SWOT, Strategi Pemasaran, In-depth interview, Focus Group Discussion, Triangulasi

\section{PENDAHULUAN}

Ada banyak cara yang dapat membuat usaha jasa penyewaan menjadi semakin maju dan berkembang. Maju dan berkembang nya usaha penyewaan dapat di lihat dari kepuasan serta kesetiaan konsumen nya dan juga konsumen baru yang didapatkan. Keberhasilan pemasaran adalah kunci sukses dari sebuah usaha (Kotler, 2002), Konsep pemasaran memiliki tujuan tersendiri yakni melayani konsumen dengan mendapatkan sejumlah keuntungan. Hal ini juga dilakukan agar perusahaan mampu memenuhi kemauan konsumen, setelah itu mencari dan melakukan cara untuk memuaskan kebutuhan konsumen tersebut. Secara garis besar pemasaran tidak hanya memiliki fungsi sebagai aktivitas menjual. Pemasaran memiliki arti yang luas yakni sebagai gabungan dari beberapa aktivitas yang dilakukan seseorang maupun kelompok, demi memenuhi kebutuhan konsumen untuk mendapatkan keuntungan sebagai tujuan akhirnya. SWOT adalah sebuah metode perencanaan strategis yang digunakan untuk mengevaluasi kekuatan, kelemahan, peluang, ancaman dalam usaha. Hal ini melibatkan penentuan tujuan usaha dan mengidentifikasi faktor-faktor internal dan eksternal yang baik dan menguntungkan untuk mencapai tujuan itu (Grewal \& Levy, 2008). SWOT ini biasa digunakan untuk menganalisis suatu kondisi dimana akan dibuat sebuah rencana untuk melakukan suatu program kerja (Buchari Alma, 2008).

Word of Mouth (WoM) adalah suatu aktifitas yang mana konsumen memberikan informasi mengenai suatu merek atau produk kepada konsumen lain (Ratna Dwi Kartika Sari, 2012). Ada 3 hal yang dapat dilakukan agar orang lain membicarakan produk atau jasa dalam buku Word of Mouth Marketing (Andy Sernovitz, 2006), yaitu: (1) Be interesting. (2) Make people happy. (3) Earn trust and respect.

Promosi adalah arus informasi atau persuasi satu arah yang dibuat untuk mengarahkan seseorang kepada tindakan yang menciptakan pertukaran dalam pemasaran. Sehingga promosi dapat diartikan sebagai suatu kegiatan yang dilakukan oleh penjual dalam usahanya untuk memaksimalkan permintaan serta membuat kesadaran kepada pelanggan tentang suatu produk atau jasa dengan jalan pemberian informasi, sampai akhirnya para calon konsumen bersedia melakukan transaksi pertukaran.

Oleh karena itu penelitian ini bertujuan untuk menganalisa SWOT dan strategi pemasaran yang di terapkan PT Panen Mas Indonesia dan dampaknya terhadap kepuasan dan kesetiaan pelanggan.

\section{METODOLOGI PENELITIAN}

Penelitian ini menggunakan metode kualitatif yang akan diadakan dengan menerapkan wawancara mendalam (in-depth interview) dan diskusi kelompok terarah (FGD).

Menurut Naresh K. Malhotra dalam bukunya Marketing Research (2010), wawancara mendalam adalah metode lain untuk memperoleh data kualitatif, wawancara mendalam tidak terstruktur dan cara langsung untuk memperoleh informasi yang dilakukan atas dasar satu-satu (hlm.185). Wawancara mendalam adalah wawancara pribadi yang tidak terstruktur, langsung, di mana satu responden diperiksa oleh pewawancara yang sangat terampil untuk mengungkap motivasi, keyakinan, sikap, dan perasaan yang mendasarinya pada suatu topik (2010, hlm. 185).

Adapun narasumber yang terkait yang akan diwawancarai mendalam (in-depth interview) yang di pilih sebagai narasumber: (1.) Dedy Loekhun Susatio (42 tahun), merupakan pendiri sekaligus pemilik PT Panen Mas Indonesia. Dijadikan narasumber karena di anggap 
sebagai orang yang mengetahui secara pasti dan akurat semua yang terjadi di dalam PT Panen Mas Indonesia, (2.) Dessy Joehan (27 tahun). merupakan bagian administrasi PT Panen Mas Indonesia yang bekerja sejak tahun 2017, merupakan orang yang mengetahui dan yang bertanggung jawab terhadap kegiatan usaha yang dilakukan PT Panen Mas Indonesia.

FGD adalah wawancara yang dilakukan oleh moderator terlatih dengan cara yang tidak terstruktur dan alami dengan sekelompok kecil responden. Moderator memimpin diskusi dengan tujuan utama kelompok terarah adalah untuk mendapatkan wawasan dengan mendengarkan sekelompok orang dari pasar sasaran yang sesuai berbicara tentang masalah yang menarik bagi peneliti seperti dikutip dari (Malhotra, N.K, 2010, hlm. 173). Selain itu, FGD akan dilakukan dengan total sepuluh partisipan yang dibagi menjadi dua kelompok dengan latar belakang sebagai pemakai jasa PT Panen Mas Indonesia. Pemilihan partisipan juga ditentukan berdasarkan peran pengalaman sehari-hari yang terkait dengan pengguna jasa. Ini bertujuan untuk memberikan informasi yang jelas tentang PT Panen Mas Indonesia. Di bawah ini adalah data partisipan FGD yang terlibat dalam penelitian: (1) Darmanto, PT Cityneon Prima Mandiri. (2) Budie Kentarti, PT Expotma Sinergi. (3) Evi, PT Debindo Adhiswati. (4) Tyara, Vc Com. (5) Bayu, PT Dyandra Promosindo, (6) William, MNC group. (7) Ryan, Cityfest. (8) Patrick, Universitas Tarumanagara. (9) Brenda, Ketua Venue jetski Asian Games 2018 (10) Asikin Zainal, Wakil Direktur Venue Asian Paragames 2018.

Validasi data penelitian ini akan menggunakan teknik triangulasi untuk memvalidasi data. Triangulasi adalah teknik pemeriksaan keabsahan data yang memanfaatkan sesuatu yang lain. Diluar data itu untuk keperluan pengecheckan atau sebagai pembanding data itu (Moleong, 2009, hlm 330). Teknik triangulasi yang paling banyak digunakan ialah pemeriksaan melalui sumber lainnya Denzin (1978) membedakan 4 macam triangulasi sebagai teknik pemeriksaan yang memanfaatkan penggunaan sumber, metode, penyidik, dan teori (Moleong, 2009, hlm. 330). Adapun penelitian ini menggunakan teknik triangulasi dengan sumber, yang berarti membandingkan dan mengecek balik derajat kepercayaan suatu informasi yang diperoleh melalui waktu dan alat yang berbeda dalam penelitian kualitatif (Patton 1987:331) diambil dari (Moleong, 2009, hlm. 330). Teknik triangulasi dengan narasumber dapat dilakukan dengan: (1) membandingkan data hasil pengamatan dengan data hasil wawancara; (2) membandingkan apa yang dikatakan orang di depan umum dengan apa yang dikatakannya secara pribadi; (3) membandingkan apa yang dikatakan orang-orang tentang situasi penelitian dengan apa yang dikatakannya sepanjang waktu; (4) membandingkan keadaan dan perspektif seseorang dengan berbagai pendapat dan pandangan orang, seperti rakyat biasa, orang berada, orang pemerintahan; (5) membandingkan hasil wawancara dengan isi suatu dokumen yang berkaitan (Moleong, 2009,hlm 331).

Penelitian ini menggunakan teknik triangulasi dikarenakan peneliti menggunakan metode wawancara secara mendalam, sehingga peneliti dapat menganalisa kredibilitas dari hasil wawancara, dengan cara membandingkan dan mengecek ulang data hasil wawancara dengan ketiga narasumber dalam penelitian ini.

\section{HASIL DAN PEMBAHASAN}

Proses pengambilan keputusan strategis selalu berkaitan dengan pengembangan visi, misi, tujuan, strategi,dan kebijakan perusahaan. Dengan demikian, perencanaan perusahaan strategis (strategicplanner) harus menganalisis faktor-faktor strategis perusahaan (kekuatan, kelemahan, peluang, dan ancaman) dalam kondisi yang ada saat ini.

Hasil analisis intermal: meliputi faktor kekuatan (strenghts), dan faktor kelemahan (weakness) PT Panen Mas Indonesia. 


\begin{tabular}{|l|l|}
\hline \multicolumn{1}{|c|}{ Keunggulan PT Panen Mas Indonesia } & \multicolumn{1}{|c|}{ Kelemahan PT Panen Mas Indonesia } \\
\hline $\begin{array}{l}\text { 1. Bekerja sama dengan perusahaan tenda merk Roder } \\
\text { (Jerman), menjadi agen resmi satu-satunya di Indonesia. } \\
\text { Tenda Roder merupakan tenda dengan konstruksi terkuat } \\
\text { di dunia. }\end{array}$ & $\begin{array}{l}\text { 1. Tidak adanya divisi sales marketing, membuat } \\
\text { pemasaran yang di lakukan menjadi kurang maksimal. }\end{array}$ \\
$\begin{array}{l}\text { 2. AC Mitsubishi Split duct 7Pk, harga investasi yang } \\
\text { sangat tinggi membuat hanya PT Panen Mas Indonesia } \\
\text { yang menyewakan AC jenis ini di JABODETABEK. }\end{array}$ & $\begin{array}{l}\text { Panen Mas terhambat dalam melakukan pekerjaan } \\
\text { acara besar. }\end{array}$ \\
$\begin{array}{l}\text { 3. Permah berpartisipasi dalam pekerjaan besar dan } \\
\text { pekerjaan intemasional (PON Jawa Barat 2016, Asian } \\
\text { Games 2018, Asian Paragames 2018). }\end{array}$ & cenderung lebih mahal dibanding perusahaan sejenis. \\
$\begin{array}{l}\text { 4. Bekeja sama dengan hampir seluruh stasiun televisi di } \\
\text { Indonesia } \\
\text { (MNC Group, Trans corp, SCTV, Indosiar, ANTV). }\end{array}$ & \\
\hline
\end{tabular}

Gambar 1

Sumber: Data Primer Peneliti

Hasil analisis eksternal: meliputi faktor kesempatan (opportunities), dan faktor ancaman (threats) PT Panen Mas Indonesia.

\begin{tabular}{|l|l|}
\hline \multicolumn{1}{|c|}{ Kesempatan PT Panen Mas Indonesia } & \multicolumn{1}{|c|}{ Ancaman PT Panen Mas Indonesia } \\
\hline $\begin{array}{l}\text { 1. Berpartisipasi dalam Pekan Olahraga Nasional, Papua } \\
\text { 2020. }\end{array}$ & $\begin{array}{l}\text { 1. PT Samudra Dyan Praga, dan PT Adicipta Warinet Jaya. } \\
\text { Dianggap sebagai kompetitor utama. Dimana kedua } \\
\text { perusahaan tersebut juga memiliki prestasi dan kualitas } \\
\text { yang baik di mata konsumen. }\end{array}$ \\
$\begin{array}{l}\text { 2. Berkembangnya usaha Event Organizer, Exhibition } \\
\text { Planner, membuat peningkatan kebutuhan permintaan } \\
\text { terhadap PT Panen Mas Indonesia. }\end{array}$ & $\begin{array}{l}\text { 2. Perusahaan yang menawarkan harga yang relatif murah } \\
\text { menjadi daya ancam tersendiri untuk PT Panen Mas } \\
\text { Indonesia. }\end{array}$ \\
$\begin{array}{l}\text { 3. Melebarkan sayap dengan membuat Event Organizer } \\
\text { sendiri. }\end{array}$ & $\begin{array}{l}\text { 3. Pandemi (COVID-19) membuat seluruh pekerjaan } \\
\text { perusahaan menjadi tertunda atau batal. }\end{array}$ \\
$\begin{array}{l}\text { 4. Fakta bahwa di beberapa negara Eropa menjadikan } \\
\text { tenda sebagai pengganti proyek pembangunan (rumah } \\
\text { tinggal, sekolah, rumah sakit) menja di kesempatan } \\
\text { apabila trend tersebut sampai masuk ke Indonesia. }\end{array}$ & \\
\hline
\end{tabular}

\section{Gambar 2}

\section{Sumber: Data Primer Peneliti}

Dari rekomendasian orang atau kekuatan Word of Mouth di nilai sebagai strategi pemasaran paling efektif yang di lakukan oleh PT Panen Mas Indonesia dimana dapat di ketahui melalui hasil wawancara dengan narasumber bahwa $80 \%$ dari total pelanggan baru itu di rekomendasikan oleh pelanggan lain nya. hal ini di dukung dengan hasil FGD yang dilakukan bahwa sembilan dari total sepuluh partisipan mengetahui dan pertama kali memakai jasa PT Panen Mas Indonesia dari teman atau rekan kerja.

Dari pembahasan di atas peneliti dapat menganalisa bahwa dari tiga jenis pemasaran yang sudah di terapkan oleh PT Panen Mas Indonesia, promosi dan Word of Mouth atau mulut ke mulut menjadi strategi pemasaran paling kuat dalam mendapatkan pelanggan baru.

Hal yang dapat dilakukan PT Panen Mas Indonesia menurut analisa peneliti guna meningkatkan jumlah pelanggan baru serta menambah kesetiaan dan kepuasan pelanggan yaitu, dengan membuat situs resmi, mengiklankan melalui media digital, dengan menambahkan divisi sales marketing, serta lebih rutin dalam mengikuti kegiatan acara pameran usaha di anggap sebagai metode pemasaran yang mungkin bisa di coba dan di terapkan PT Panen Mas Indonesia kedepan nya. Di ketahui dari hasil wawancara kepada semua narasumber dan di dukung oleh seluruh partisipan FGD bahwa PT Panen Mas Indonesia memberikan promosi, peneliti juga menilai promosi harga menjadi daya tarik sendiri untuk menarik pelanggan baru juga menimbulkan rasa setia dari pelanggan lama, hal ini di dukung oleh hasil FGD dimana sepuluh dari sepuluh partisipan akan sangat senang dan ingat akan PT Panen Mas Indonesia saat memberlakukan promosi harga. 


\section{KESIMPULAN DAN SARAN}

Dari keseluruhan hasil analisis yang dilakukan oleh peneliti dapat di simpulkan bahwa PT Panen Mas Indonesia memiliki beberapa keunggulan berbeda dari kualitas alat-alat kontraktor acara di bandingkan dengan perusahaan sejenis lain nya, melihat potensi PT Panen Mas Indonesia yang dapat lebih berkembang dan maju dapat di simpulkan juga bahwa strategi pemasaran yang di terapkan PT Panen Mas Indonesia saat ini masih belum maksimal, serta perusahaan masih memiliki beberapa kelemahan dan kekurangan, hal ini dapat di ketahui berdasarkan hasil in-depth interview dan FGD bahwa perusahaan belum memiliki divisi sales marketing, masih melakukan double job, serta belum mempunyai situs resmi (website), kantor remi yang mungkin menjadi salah satu penghambat atau belum maksimalnya pemasaran yang dilakukan perusahaan. Secara akademis, tesis ini dapat digunakan sebagai referensi untuk studi di masa depan. Penelitian ini dilakukan dengan metode kualitatif yang bersifat deskriptif dalam menilai suatu masalah yang sedang terjadi. Oleh sebab itu, penggunaan teori dan konsep yang relevan dan sesuai terhadap SWOT serta strategi pemasaran yang dii terapkan oleh PT Panen Mas Indonesia dan dampaknya terhadap kepuasan dan kesetiaan pelanggan dapat dianalisa secara lebih mendalam dengan menggunakan konsep-konsep lain yang relevan dengan hasil temuan penelitian. Saran secara praktis yang dapat di berikan kepada PT Panen Mas Indonesia yakni perusahaan ini perlu menerapkan strategi-strategi pemasaran yang baru, seperti menambahkan divisi sales marketing, menambah jumlah pekerja, membuat website resmi, iklan, menjadi sponsor suatu acara sebagai ajang promosi, Dengan begitu PT Panen Mas Indonesia dapat menjadi perusahaan exhibition contractor yang semakin di kenal dan di percaya.

\section{DAFTAR PUSTAKA}

Ardianto, E. (2014). Metodologi Penelitian Untuk Public Relations. Bandung: Simbiosa Rekatama Media.

Baduara. (2004). Salesmanship Ilmu Seni \& Seni Menjadi Penjual yang Sukses. PT Bumi Aksara. Jakarta.

Buchari, A. (2008). Manajemen Pemasaran dan Pemasaran Jasa. Bandung: Alfabeta.

Bungin, B. (2010). Penelitian Kualitatif. Prenada Media Group.

Daymond. C., \& Holloway, I. (2002). Qualitative Research Metods In Public Relations \& Marketing Communications. London: Routledge.

Denzin, N., \& Lincoln, Y. (2009). Handbook of Qualitative Research. Yogyakarta: Pustaka Pelajar.

Grewal, \& Levy. (2008). Marketing. New York: Pearson Prentice Hall.

Gundono. (2011). Analisis Data Multivarat. Yogyakarta: BPFE Yogyakarta.

Indrawati. I. (2019). Analisis faktor yang mempengaruhi pembentukan minat berlangganan di industri video-on demand di Indonesia.

Kotler, P., \& Amstrong, G. (2010) Principles of Marketing (13 ${ }^{\text {th }}$ ed.). United States of America: Pearson.

Kotler, P. (2002). Manajemen Pemasaran (Edisi Milenium, Jilid 1). Jakarta: PT Prehallindo.

Malhotra, N. K. (2010). Marketing Research: An Applied Orientation (6 ${ }^{\text {th }}$ ed.). New Jersey: Pearson Education Inc.

Moleong, L. J. (2010). Metodologi Penelitian Kualitatif (28 $8^{\text {th }}$ ed.). Bandung: PT Remaja Rosdakarya.

Sari, R. D. K. (2012). Analisis pengaruh kualitas produk, persepsi harga \& word of mouth communication terhadap keputusan pembelian mebel pada CV Mega Jaya Mebel. Semarang.

Sernovitz, A. (2006). Word of Mouth Marketing: How Smart Companies Get People Talking. Sugiono. (2010). Memahami Penelitian Kualitatif. Bandung: Alfabeta.

Swastha, B., \& Irawan. (2005). Manajemen Pemasaran Modern Liberty. Yogyakarta. 